\title{
Growth Characteristics Modeling of Lactobacillus acidophilus using RSM and ANN
}

\author{
Ganga Sahay Meena ${ }^{1 *}$, Nitin Kumar ${ }^{1}$, Gautam Chandra Majumdar ${ }^{1}$, Rintu Banerjee ${ }^{1}$, \\ Pankaj Kumar Meena ${ }^{2}$ and Vijesh Yadav ${ }^{2}$ \\ ${ }^{I}$ Microbial Biotechnology and Downstream Processing Laboratory; Department of Agricultural and Food \\ Engineering; Indian Institute of Technology; Kharagpur. ${ }^{2}$ By Product Laboratory; Dairy Technology Division \\ National Dairy Research Institute; Karnal - Haryana
}

\begin{abstract}
The culture conditions viz. additional carbon and nitrogen content, inoculum size, age, temperature and pH of Lactobacillus acidophilus were optimized using response surface methodology (RSM) and artificial neural network $(A N N)$. Kinetic growth models were fitted to cultivations from a Box-Behnken Design (BBD) design experiments for different variables. This concept of combining the optimization and modeling presented different optimal conditions for L. acidophilus growth from their original optimization study. Through these statistical tools, the product yield (cell mass) of L. acidophilus was increased. Regression coefficients $\left(R^{2}\right)$ of both the statistical tools predicted that ANN was better than RSM and the regression equation was solved with the help of genetic algorithms (GA). The normalized percentage mean squared error obtained from the ANN and RSM models were 0.06 and $0.2 \%$, respectively. The results demonstrated a higher prediction accuracy of ANN compared to RSM.
\end{abstract}

Key words: Response surface methodology (RSM), Artificial neural network (ANN), Genetic algorithms (GA), Box-behnken besign (BBD)

\section{INTRODUCTION}

Lactobacillus is the most prominent members of plethora class of bacterial species with probiotic properties. The popularity of these group bacteria is based on the millennia of use in food and feed that are used in probiotic dairy drinks and yoghurts since hundred years (Sanders 1999). Most bacterial species of this class are formally classified as GRAS (generally recognized as safe) organisms. Currently, consumers are very much concerned about the nutritional and functional attributes of food worldwide. A number of health benefits such as anti-mutagenic effects, anticarcinogenic properties, improvement in lactose metabolism, reduction in serum cholesterol and immune system stimulation have been claimed for probiotic foods, which fall in the category of functional foods (Shah 2007). Consequently, the global functional food market is thriving with recent estimates indicating up to a $\$ 50$ billion annual share. The world probiotic market is estimated at $\$ 15$ billions, which included $10 \%$ of the lactic bacteria drink market. Today, this market is growing at a pace of 5 to $30 \%$ depending on the country and product type. Although the worldwide market for probiotics is growing rapidly, yet, in India, it has just started to gestate for making its first move with leading companies such as Amul, Nestle and Mother Dairy (Bhadoria and Mahapatra 2011). Probiotics have a strong stimulatory effect for both the normal development of microbiota

*Author for correspondence: gsmndri@gmail.com 
and maturation of gut associated lymphoid tissue (Schezenmeir and De Vrese 2001). Probiotic bacteria such as Lactobacillus and Bifidobacterium sp can play an important role in promoting human health in the gastrointestinal tract (Mitsuoka 1990). They actively contribute in the digestion, immune stimulation and inhibition of pathogens such as Bacteroides, Escherichia, Clostriduim and Proteus, which are potentially harmful bacteria found in the gastrointestinal tract (Ziemer and Gibson 1998).

The primary mechanism for probiotic action is known as competitive colonization, or competitive suppression. It is best described as the proliferation of probiotic bacteria in the human intestine, leaving little space for the growth of any pathogens. Further, they secrete by-products such as lactic acid and acetic acid, which lower the $\mathrm{pH}$, thereby creating a hostile environment for the growth of pathogenic microorganism. The secreted acids also increase the peristalsis, which also help to speed pathogens though the intestines (Ballongue 1992 and Biavati et al. 2000).

To develop the growth model of probiotic bacteria through the traditional method, i.e., one variable at-a-time (OVAT) is time consuming and neglects interactions of different variables which can also affect the yield. Process optimization through statistical method is a technique in which changes or adjustments are made in a process to get better results (Myers and Montgomery 2002). There are several techniques for process optimization such as Response Surface Methodology (RSM), Artificial Neural Networks (ANN), Genetic Algorithms (GA), etc. In these engineering applications, a response of interest is usually influenced by several variables and the objective of the engineering applications is to find the variables that can optimize the response. RSM is a tool to study the optimal process parameters that produce a maximum, or minimum value of the response and represents the direct and interactive effects of the process parameters through two and three-dimensional plots (Gangadharan et al. 2008). ANN is computational models of nervous systems. Natural organisms, however, do not possess only nervous systems but also genetic information stored in the nucleus of their cells (genotype). The nervous system is part of the phenotype, which is derived from this genotype through a process, called development (Rajasekaran and Vijaylakshmi 2004). Using the method of neural networks $(\mathrm{NN})$, the relationship between a set of independent variables $X$ and the dependent variables $Y$ can be obtained. From the given pairs of input $X$ and output $Y$ data, neural network directly learns and develops a relationship between them but does not yield any mathematical equation relating the variables. After the learning, this network is able to predict the correct output from an input data set that has not been previously used during the learning. GA is a tool by which the optimization problems can be accurately solved with in a limited use of computer time (Das 2005). Optimization of various bacterial strains in Erlenmeyer flasks using different optimization tools have been reported by several other authors (Nagarjun et al. 2005; Kumari et al. 2009; Negi and Banergee 2009; Lima et al. 2009; Usmiati and Marwati 2009; Coelho et al. 2011).

This study developed the empirical model to increase the cell growth of $L$. acidophilus by optimizing growth parameters such as temperature, $\mathrm{pH}$, inoculum volume, incubation period and additional effect of different carbon and nitrogen sources using the RSM, ANN and GA.

\section{MATERIAL AND METHODS}

\section{Chemicals}

All the solvents and reagents used in the present study were procured from Merck, Germany.

\section{Organism and growth condition}

Pure culture of $L$. acidophilus NCDC 14 was obtained in freeze dried state from National Collection of Dairy Cultures (NCDC), National Dairy Research institute, Karnal, Haryana, India. The culture was maintained at $4^{\circ} \mathrm{C}$ and subcultured on the slants of MRS (De Man Rogosa and Sharpe) growth medium two times in a month. The method used for the microbial culture activation and pellet extraction was same as reported by Sharma et al. (2013). The growth of $L$. acidophilus was carried out in $250 \mathrm{~mL}$ Erlenmeyer flasks each containing $50 \mathrm{~mL}$ MRS agar medium (pH 7.0) and maintained at $37^{\circ} \mathrm{C}$. The cell biomass was determined by measuring the optical density (OD) of the medium at $600 \mathrm{~nm}$. Before measuring the OD, the liquid containing cells were centrifuged and washed with sterile distilled water for two times to remove the adhering medium constituents. 


\section{Experimental Design}

Selection of initial parameters

For the selection of initial parameters, 'one variable at a time method' was used. The different variables viz. temperature, $\mathrm{pH}$, volume of inoculum, age of inoculum and additional carbon and nitrogen sources were selected for the growth of L. acidophilus.

\section{Empirical model development}

In order to find the effect of different growth parameters on the predicted value of bacterial growth $Y_{p}$ was obtained by conducting the experiments on different combination of independent variables (growth parameters), which was obtained from a standard experimental design. During the experiments, the response, or values of dependent variables obtained from each of the combinations of independent variables was measured. A mathematical relationship between the independent and dependent variables was developed. Using this model, the predicted value of response were find out within the domain of limiting values of independent variables.

For the different growth parameters it was desired to develop a polynomial model between the Lactobacillus growth and growth parameters to develop the following relationship between the coded values $x_{1}, x_{2}, x_{3}, x_{4}, x_{5}$ and $x_{6}$ of independent variables and dependent variable $Y_{p}$ as shown below.

$Y p=b_{o}+b_{1} x_{1}+b_{2} x_{2}+b_{3} x_{3}+b_{4} x_{4}+b_{5} x_{5}+b_{6} x_{6}+b_{7} x_{1}^{2}+b_{8}$ $x_{2}{ }^{2}+b_{9} x_{3}{ }^{2}+b_{10} x_{4}{ }^{2}+b_{11} x_{5}{ }^{2}+b_{12} x_{6}{ }^{2}+b_{13} x_{1} x_{2}+b_{14} x_{1} x_{3}+b$ ${ }_{15} x_{1} x_{4}+b_{16} x_{1} x_{5}+b_{17} x_{1} x_{6}+b_{18} x_{2} x_{3}+b_{19} x_{2} x_{4}+b_{20} x_{2} x_{5}+b_{2}$ ${ }_{1} x_{2} x_{6}+b_{22} x_{3} x_{4}+b_{23} x_{3} x_{5}+b_{24} x_{3} x_{6}+b_{25} x_{4} x_{5}+b_{26} x_{4} x_{6}+b_{27}$ $x_{5} x_{6} \quad$ (Eq. 1)

Where $b_{o}, b_{1}, b_{2} \ldots \ldots .$. etc. are the regression constants.

\section{Experimental Modeling}

\section{Box-Behnken Design}

Optimization process involving OVAT method was only used for the selection of initial parameters while RSM was adopted to optimize the growth conditions for L. acidophilus by BoxBehnken design. MINITAB (version 6.5) software was used for the experimental design.

\section{Optimization}

\section{Artificial neural network modeling}

In this present investigation, a feed forward back propagation neural network was used to evaluate its capability in cell mass yield prediction of
L. acidophilus. In this process, ANN computed the error between the desired (predicted) response and the actual (experimental) response. The number of neurons in input layer, hidden layer and output layer of this neural network were kept as 6,11 and 1, respectively (Fig. 1). This ANN was first trained with reported data of $B$. bifidum (Meena et al. 2011). After training, it was able to predict the cell mass yield of $L$. acidophilus accurately through error minimization that was compared with the predicted value of cell mass yield obtained from RSM.

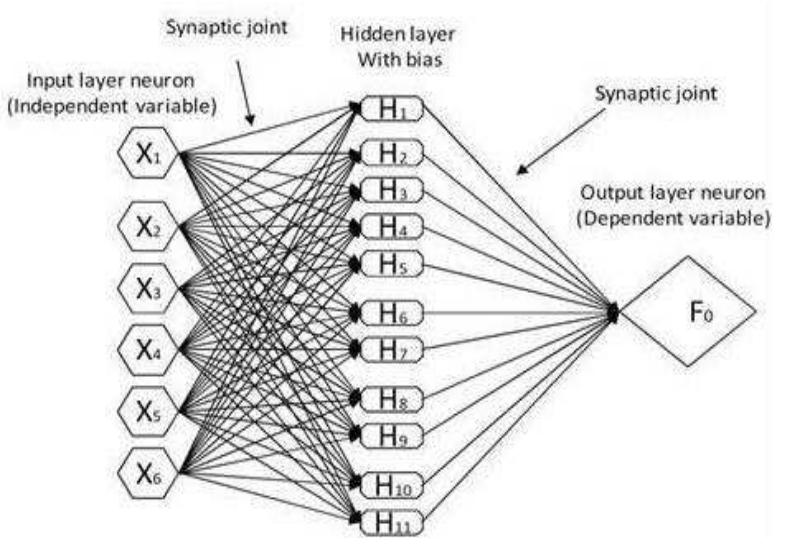

Figure 1 - Basic structure of a feed forward back propagation neural network (Meena et al. 2011).

\section{Genetic Algorithms}

In order to maximize the cell mass yield of $L$. acidophilus, GA was applied to the developed ANN based model (Fig. 2) by monitoring above mentioned six growth parameters. It was posed as the minimization of problem associated with the optimization studies. Genetic optimization was continued till the maximum cell mass yield obtained.

\section{Software used}

For the proper execution of ANN and GA, MATLAB 7.0 and MINITAB 6.5 was used to develop the empirical model.

\section{RESULTS AND DISCUSSION}

\section{Selection of initial parameters}

Different growth variables for L. acidophilus were selected by OVAT method and results showed in Figure $3(\mathrm{~A}-\mathrm{F})$. All these parameters, their variation and optimum values are given in Table 1. 


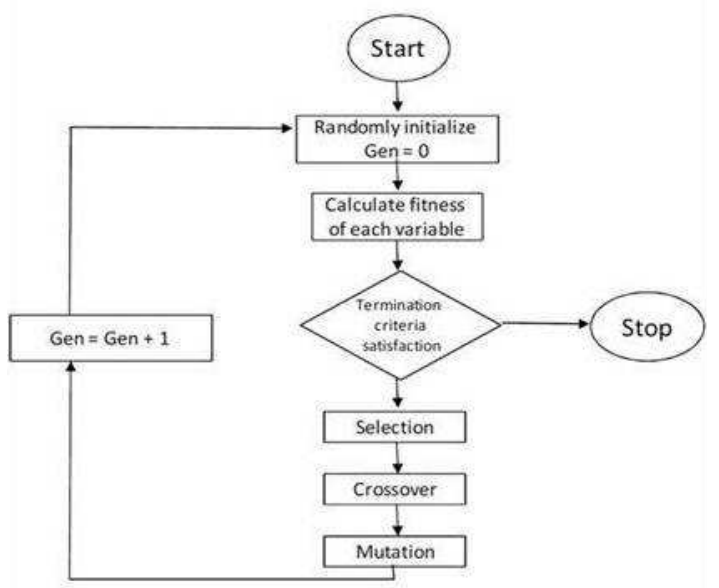

Figure 2 - Flow chart of simple genetic algorithms (Meena et al. 2011).

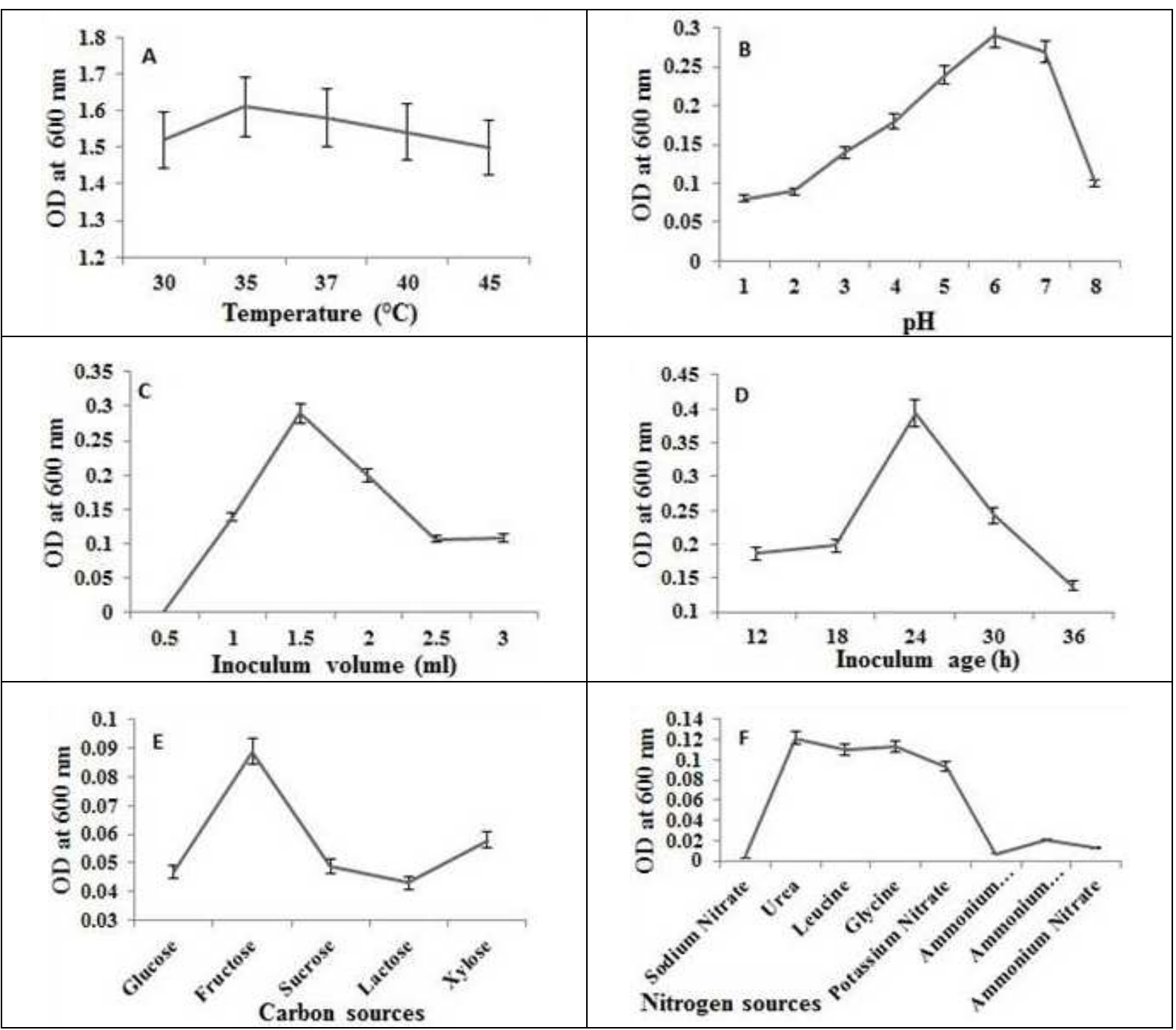

Figure 3 - Selection of different parameters for Lactobacillus acidophilus growth (A. Selection of initial temperature for. L. acidophilus growth, B. Selection of initial $\mathrm{pH}$ for L. acidophilus growth, C. Selection of initial inoculun volume for L. acidophilus 255 growth, D. Selection of initial incubation period for L. acidophilus growth, E. Selection of suitable carbon source for L. acidophilus growth and F. Selection of suitable nitrogen source for growth). 
Table 1 - Values of different parameters for single parameter optimization.

\begin{tabular}{lll}
\hline Different growth parameters & Variation of parameters & Maximum growth on parameter \\
\hline Temperature, $\left({ }^{\circ} \mathrm{C}\right)$ & $30,35,37,40,45$ & 35 \\
$\mathrm{pH}$ & $1.0,2.0,3.0,4.0,5.0,6.0,7.0,8.0$ & 6.0 \\
Inoculum Volume, $(\mathrm{mL})$ & $0.5,1.0,1.5,2.0,2.5,3.0$ & 1.5 \\
Inoculum age, $(\mathrm{h})$ & $12,18,24,30,36$ & 24 \\
Carbon sources, $(\% \mathrm{w} / \mathrm{v})$ & Glucose, Fructose, Sucrose Lactose, Xylose & Fructose \\
Nitrogen sources, $(\% \mathrm{w} / \mathrm{v})$ & $\begin{array}{l}\text { Sodium nitrate, Urea, Leucine, Glycine, } \\
\text { Potassium nitrate, Ammonium sulphate, }\end{array}$ & Urea \\
& Ammonium chloride, Ammonium nitrate & \\
\hline
\end{tabular}

\section{Empirical model development}

From the initial parameter selection, the maximum and minimum values of six independent parameters for $L$. acidophilus were fixed as shown in Table 2. It was one of the objectives to develop the model between coded values $x_{1}, x_{2}, x_{3}, x_{4}, x_{5}$ and $x_{6}$ of independent variables and dependent variable $Y_{p}$. For this, experiments were conducted according to Box-Behnken design. All these combinations are given in Table 3 with their corresponding experimental value $Y_{e}$ for the growth of L. acidophilus.
Table 2 - Limiting value of independent variables.

\begin{tabular}{lcc}
\hline Parameters & $\begin{array}{c}\text { Maximum } \\
\text { value }\end{array}$ & $\begin{array}{c}\text { Minimum } \\
\text { value }\end{array}$ \\
\hline Temperature, $\left({ }^{\circ} \mathrm{C}\right)$ & 45 & 30 \\
$\mathrm{pH}$ & 8 & 1.0 \\
Inoculum volume, $(\mathrm{ml})$ & 3 & 0.5 \\
Inoculum age, $(\mathrm{h})$ & 36 & 12 \\
Carbon content, $(\% \mathrm{w} / \mathrm{v})$ & 42.06 & 30 \\
Nitrogen content, $(\% \mathrm{w} / \mathrm{v})$ & 46.67 & 14 \\
\hline
\end{tabular}

Table 3 - Experimental design for Lactobacillus acidophilus with experimental value $Y_{e}$.

\begin{tabular}{|c|c|c|c|c|c|c|c|c|c|c|}
\hline $\begin{array}{l}\text { Std. } \\
\text { order }\end{array}$ & $\begin{array}{c}\text { Run } \\
\text { order }\end{array}$ & $\underset{\text { type }}{\mathbf{P t}}$ & Block & ${ }^{\text {Temp. }}$ & $\begin{array}{l}\text { pH } \\
\left(x_{2}\right) \text { vo }\end{array}$ & $\begin{array}{l}\text { Inoculum } \\
\text { lume }(\mathrm{ml})\left(x_{3}\right)\end{array}$ & $\begin{array}{c}\text { Inoculum } \\
\text { age }(\mathbf{h})\left(x_{4}\right)\end{array}$ & $\begin{array}{l}\text { Carbon } \\
\text { content } \\
\% \text { w/v }\left(x_{5}\right)\end{array}$ & $\begin{array}{c}\text { Nitrogen } \\
\text { content } \\
\% \text { w/v }\left(x_{6}\right)\end{array}$ & $\underset{\text { value }\left(Y_{e}\right)}{\text { Experimental }}$ \\
\hline 36 & 1 & 2 & 1 & 37.5 & 6 & 3 & 36 & 40.5 & 46 & 2.063 \\
\hline 5 & 2 & 2 & 1 & 37.5 & 4 & 3 & 24 & 39 & 30 & 0.166 \\
\hline 52 & 3 & 0 & 1 & 30 & 6 & 3 & 24 & 40.5 & 46 & 0.642 \\
\hline 39 & 4 & 2 & 1 & 37.5 & 6 & 1.75 & 24 & 40.5 & 30 & 0.348 \\
\hline 1 & 5 & 2 & 1 & 30 & 6 & 1.75 & 36 & 42 & 30 & 0.945 \\
\hline 31 & 6 & 2 & 1 & 30 & 6 & 0.5 & 24 & 40.5 & 14 & 0.44 \\
\hline 54 & 7 & 0 & 1 & 37.5 & 8 & 3 & 24 & 39 & 30 & 0.775 \\
\hline 8 & 8 & 2 & 1 & 30 & $\begin{array}{l}0 \\
4\end{array}$ & 1.75 & 36 & 40.5 & 30 & 0.589 \\
\hline 27 & 9 & 2 & 1 & 45 & 6 & 0.5 & 24 & 40.5 & 46 & 0.014 \\
\hline 13 & 10 & 2 & 1 & 37.5 & 8 & 1.75 & 24 & 39 & 46 & 0.901 \\
\hline 47 & 11 & 2 & 1 & 37.5 & $\begin{array}{l}8 \\
8\end{array}$ & 1.75 & 24 & 42 & $\begin{array}{l}40 \\
14\end{array}$ & $\begin{array}{l}0.901 \\
0.753\end{array}$ \\
\hline 41 & 12 & 2 & 1 & 37.5 & 8 & 1.75 & 24 & 39 & 14 & 0.712 \\
\hline 25 & 13 & 2 & 1 & 37.5 & $\begin{array}{l}0 \\
6\end{array}$ & 1.75 & 24 & 40.5 & 30 & 0.382 \\
\hline 35 & 14 & 2 & 1 & 37.5 & 6 & 3 & 36 & 40.5 & 14 & 1.115 \\
\hline 45 & 15 & 2 & 1 & 45 & 8 & 1.75 & 36 & 40.5 & 30 & 0.222 \\
\hline 30 & 16 & 2 & 1 & 30 & $\begin{array}{l}\circ \\
8\end{array}$ & 1.75 & 12 & 40.5 & 30 & 1.337 \\
\hline 3 & 17 & 2 & 1 & 37.5 & $\begin{array}{l}0 \\
6\end{array}$ & 1.75 & 24 & 40.5 & 30 & 0.412 \\
\hline 48 & 18 & 2 & 1 & 30 & 6 & 3 & 24 & 40.5 & 14 & 0.543 \\
\hline 49 & 19 & 0 & 1 & 30 & 8 & 1.75 & 36 & 40.5 & 30 & 0.951 \\
\hline 9 & 20 & 2 & 1 & 37.5 & 6 & 1.75 & 24 & 40.5 & 30 & 0.337 \\
\hline 6 & 21 & 2 & 1 & 37.5 & 4 & 3 & 24 & 42 & 30 & 0.168 \\
\hline $\begin{array}{l}0 \\
46\end{array}$ & $\begin{array}{l}21 \\
22\end{array}$ & 2 & 1 & $\begin{array}{l}3.5 \\
37.5\end{array}$ & $\begin{array}{l}4 \\
8\end{array}$ & 0.5 & $\begin{array}{l}24 \\
24\end{array}$ & $\begin{array}{l}42 \\
42\end{array}$ & $\begin{array}{l}30 \\
30\end{array}$ & $\begin{array}{l}0.108 \\
0.827\end{array}$ \\
\hline 20 & 23 & 2 & 1 & 37.5 & $\begin{array}{l}0 \\
4\end{array}$ & 0.5 & 24 & 39 & 30 & 0.094 \\
\hline 15 & 24 & 2 & 1 & 37.5 & 6 & 0.5 & 12 & 40.5 & 46 & 2.301 \\
\hline 4 & 25 & 2 & 1 & 45 & 8 & 1.75 & 12 & 40.5 & 30 & 0.407 \\
\hline $\begin{array}{l}4 \\
16\end{array}$ & 26 & 2 & 1 & 37.5 & $\begin{array}{l}8 \\
4\end{array}$ & 1.75 & 24 & 39 & $\begin{array}{l}30 \\
14\end{array}$ & $\begin{array}{c}0.401 \\
0.18\end{array}$ \\
\hline $\begin{array}{l}10 \\
7\end{array}$ & $\begin{array}{l}20 \\
27\end{array}$ & 2 & 1 & 30 & $\begin{array}{l}4 \\
6\end{array}$ & $\begin{array}{l}1.15 \\
1.75\end{array}$ & $\begin{array}{l}24 \\
12\end{array}$ & $\begin{array}{l}39 \\
42\end{array}$ & $\begin{array}{l}14 \\
30\end{array}$ & $\begin{array}{l}0.289 \\
1.289\end{array}$ \\
\hline 22 & 28 & 2 & 1 & 30 & 6 & 0.5 & 24 & 40.5 & 46 & 0.733 \\
\hline 24 & 29 & 2 & 1 & 37.5 & 4 & 1.75 & 24 & 39 & 46 & 0.084 \\
\hline 50 & 30 & 0 & 1 & 45 & 6 & 1.75 & 12 & 42 & 30 & 0.171 \\
\hline 37 & 31 & 2 & 1 & 30 & 4 & 1.75 & 12 & 40.5 & 30 & $\begin{array}{l}.1 .048 \\
0.048\end{array}$ \\
\hline 43 & 32 & 2 & 1 & 37.5 & 8 & 3 & 24 & 42 & 30 & 0.285 \\
\hline 2 & 33 & 2 & 1 & 45 & 6 & 1.75 & 36 & 42 & 30 & 0.524 \\
\hline 34 & 34 & 2 & 1 & 37.5 & 4 & 1.75 & 24 & 42 & 14 & 0.064 \\
\hline 38 & 35 & 2 & 1 & 45 & 6 & 3 & 24 & 40.5 & 14 & 0.197 \\
\hline
\end{tabular}




\begin{tabular}{|c|c|c|c|c|c|c|c|c|c|c|}
\hline $\begin{array}{c}\text { Std. } \\
\text { order }\end{array}$ & $\underset{\text { order }}{\text { Run }}$ & $\underset{\text { type }}{P t}$ & Block & $\underset{{ }^{0} \mathrm{C}\left(x_{1}\right)}{\text { Temp. }}$ & $\begin{array}{l}\mathrm{pH} \\
\left(x_{2}\right) \mathrm{vo}\end{array}$ & $\begin{array}{l}\text { Inoculum } \\
\text { lume }(\mathrm{ml})\left(x_{3}\right)\end{array}$ & $\begin{array}{l}\text { Inoculum } \\
\text { age }(h)\left(x_{4}\right)\end{array}$ & $\begin{array}{c}\text { Carbon } \\
\text { content } \\
\% \text { w/v }\left(x_{5}\right)\end{array}$ & $\begin{array}{c}\text { Nitrogen } \\
\text { content } \\
\% \text { w/v }\left(x_{6}\right)\end{array}$ & $\begin{array}{c}\text { Experimental } \\
\text { value }\left(Y_{e}\right)\end{array}$ \\
\hline 11 & 36 & 2 & 1 & 37.5 & 6 & 3 & 12 & 40.5 & 14 & 0.003 \\
\hline 42 & 37 & 2 & 1 & 30 & 6 & 1.75 & 12 & 39 & 30 & 0.328 \\
\hline 44 & 38 & 2 & 1 & 37.5 & 4 & 0.5 & 24 & 42 & 30 & 0.049 \\
\hline 26 & 39 & 2 & 1 & 45 & 4 & 1.75 & 36 & 40.5 & 30 & 0.245 \\
\hline 53 & 40 & 0 & 1 & 37.5 & 6 & 1.75 & 24 & 40.5 & 30 & 0.089 \\
\hline 12 & 41 & 2 & 1 & 37.5 & 6 & 0.5 & 36 & 40.5 & 46 & 0.212 \\
\hline 51 & 42 & 0 & 1 & 45 & 6 & 1.75 & 12 & 39 & 30 & 0.183 \\
\hline 28 & 43 & 2 & 1 & 37.5 & 6 & 3 & 12 & 40.5 & 46 & 0.314 \\
\hline 23 & 44 & 2 & 1 & 37.5 & 6 & 1.75 & 24 & 40.5 & 30 & 0.135 \\
\hline 19 & 45 & 2 & 1 & 37.5 & 8 & 0.5 & 24 & 39 & 30 & 0.165 \\
\hline 10 & 46 & 2 & 1 & 37.5 & 8 & 1.75 & 24 & 42 & 46 & 0.13 \\
\hline 21 & 47 & 2 & 1 & 30 & 6 & 1.75 & 36 & 39 & 30 & 0.667 \\
\hline 29 & 48 & 2 & 1 & 45 & 6 & 3 & 24 & 40.5 & 46 & 0.2 \\
\hline 17 & 49 & 2 & 1 & 37.5 & 6 & 0.5 & 36 & 40.5 & 14 & 0.231 \\
\hline 18 & 50 & 2 & 1 & 45 & 6 & 0.5 & 24 & 40.5 & 14 & 0.176 \\
\hline 14 & 51 & 2 & 1 & 37.5 & 6 & 0.5 & 12 & 40.5 & 14 & 0.105 \\
\hline 33 & 52 & 2 & 1 & 45 & 6 & 1.75 & 36 & 39 & 30 & 0.551 \\
\hline 40 & 53 & 2 & 1 & 45 & 4 & 1.75 & 12 & 40.5 & 30 & 0.057 \\
\hline 32 & 54 & 2 & 1 & 37.5 & 4 & 1.75 & 24 & 42 & 46 & 0.116 \\
\hline
\end{tabular}

RSM is mainly used for optimization of growth conditions, reaction parameter, or scaling up the $L$. acidophilus growth conditions (Sen and Babu 2005). Experimental data were fitted to the full quadratic equation and the design matrix and the fitness of each term was analyzed by the means of ANOVA (Kumari et al. 2008). Figure 4 shows the corresponding model coefficients $\left(R^{2}\right.$ 0.796) together with the regression coefficient of determination, which was a measure of how well the regression model could be made to fit the raw data.

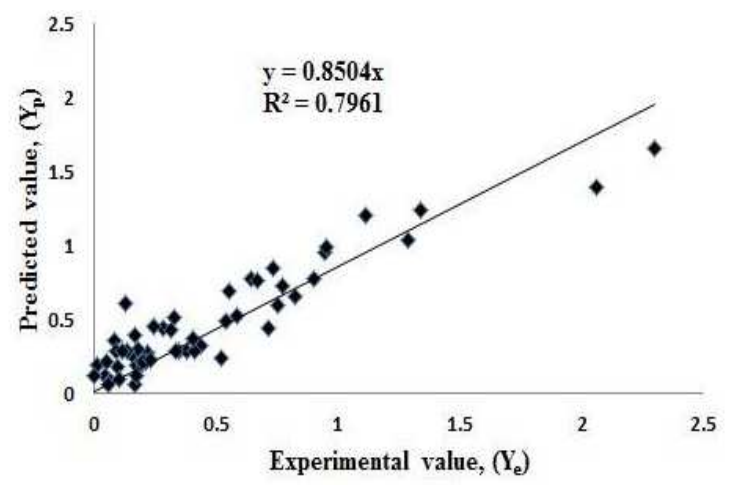

Figure 4 - Determination of regression equation coefficient $\mathrm{R}^{2}$ for Lactobacillus acidophilus EMD method.

A self-organizing feature map network was used to predict the growth condition parameters. Different factors, viz. temperature, $\mathrm{pH}$, inoculums volume, inoculums age and additional carbon and nitrogen sources were used as each unit of input layer. The output layer was composed of one response variable, the growth of $L$. acidophilus. A set of factors was used for training and fed into the computer. Several iterations were conducted with different numbers of neurons of hidden layer in order to determine the optimal ANN structure. The optimum number of neurons in the hidden layer was iteratively determined by changing the number of neurons. It started with two neurons and was increased up to six. The least MSE value and a good prediction of the outputs of both training and validation sets were obtained with four neurons in the hidden layer (Dutta et al. 2004). The $\mathrm{R}^{2}$ value between the actual and estimated responses was determined as 0.927 (Fig. 5). In ANN modeling, the replicates at center point did not improve the prediction capability of the network because of the similar inputs.

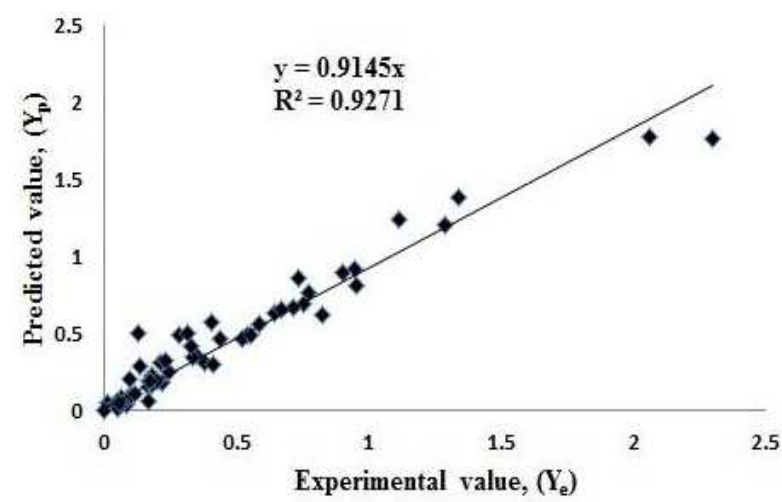

Figure 5 - Determination of regression equation coefficient $\mathrm{R}^{2}$ for Lactobacillus acidophilus ANN method. 
Using MATLAB 7.0, the constants of regression equation and predicted value of dependent variable (OD) were find out. The obtained model for $L$. acidophilus was as given below.

$Y_{p}=0.2838-0.2319 x_{1}+0.2335 x_{2}+0.0468 x_{3}+$ $0.738 x_{4}+0.0215 x_{5}+0.133 x_{6}-0.082 x_{1}^{2}-$ $0.0627 x_{2}^{2}+0.0575 x_{3}^{2}+0.3429 x_{4}^{2}+0.0327 x_{5}^{2}+$ $0.0375 x_{6}^{2}-0.1088 x_{1} x_{2}-0.1655 x_{1} x_{3}+0.0244 x_{1} x_{4}+$ $0.0359 x_{1} x_{5}-0.1597 x_{1} x_{6}-0.0689 x_{2} x_{3}-0.0154 x_{2} x_{4}-$
$0.1625 x_{2} x_{5}-0.0487 x_{2} x_{6}+0.603 x_{3} x_{4}-0.1381 x_{3} x_{5}$ $-0.0592 x_{3} x_{6}-0.0873 x_{4} x_{5}-0.1972 x_{4} x_{6}-0.083 x_{5} x_{6}$ (Eq. 2)

The predicted value of independent variable and corresponding experimental value for $L$. acidophilus is shown in the Table 4. Genetic algorithms were applied on the data obtained from neural network using MATLAB7.0.

Table 4 - Experimental and predicted values for Lactobacillus acidophilus using RSM and ANN.

\begin{tabular}{|c|c|c|c|c|c|}
\hline $\begin{array}{c}\text { Experimental } \\
\text { values } Y_{e} \\
\end{array}$ & $\begin{array}{c}\text { Predicted values } \\
Y_{p}(\mathrm{RSM}) \\
\end{array}$ & $\begin{array}{c}\text { Predicted values } \\
Y_{p}(\mathrm{ANN}) \\
\end{array}$ & $\begin{array}{c}\text { Experimental } \\
\text { values } Y_{e} \\
\end{array}$ & $\begin{array}{c}\text { Predicted values } \\
Y_{p}(\mathrm{RSM}) \\
\end{array}$ & $\begin{array}{c}\text { Predicted } \\
\text { values } Y_{p}(\mathrm{ANN})\end{array}$ \\
\hline 2.063 & 1.39 & 1.77 & 0.733 & 0.84 & 0.86 \\
\hline 0.166 & 0.23 & 0.157 & 0.084 & 0.35 & 0.03 \\
\hline 0.642 & 0.77 & 0.635 & 0.171 & 0.19 & 0.19 \\
\hline 0.348 & 0.28 & 0.35 & 0.048 & 0.11 & 0.05 \\
\hline 0.945 & 0.95 & 0.91 & 0.285 & 0.44 & 0.489 \\
\hline 0.44 & 0.32 & 0.46 & 0.524 & 0.23 & 0.46 \\
\hline 0.775 & 0.72 & 0.76 & 0.064 & 0.08 & 0.08 \\
\hline 0.589 & 0.52 & 0.56 & 0.197 & 0.2 & 0.185 \\
\hline 0.014 & 0.19 & 0.04 & 0.003 & 0.11 & 0.002 \\
\hline 0.901 & 0.77 & 0.89 & 0.328 & 0.51 & 0.41 \\
\hline 0.753 & 0.59 & 0.69 & 0.049 & 0.21 & 0.011 \\
\hline 0.712 & 0.44 & 0.67 & 0.245 & 0.45 & 0.25 \\
\hline 0.382 & 0.28 & 0.31 & 0.089 & 0.28 & 0.08 \\
\hline 1.115 & 1.2 & 1.234 & 0.212 & 0.21 & 0.31 \\
\hline 0.222 & 0.27 & 0.17 & 0.183 & 0.29 & 0.22 \\
\hline 1.337 & 1.24 & 1.38 & 0.314 & 0.43 & 0.5 \\
\hline 0.412 & 0.28 & 0.3 & 0.135 & 0.28 & 0.28 \\
\hline 0.543 & 0.48 & 0.49 & 0.165 & 0.39 & 0.19 \\
\hline 0.951 & 0.99 & 0.81 & 0.13 & 0.6 & 0.5 \\
\hline 0.337 & 0.28 & 0.34 & 0.667 & 0.76 & 0.649 \\
\hline 0.168 & 0.06 & 0.06 & 0.2 & 0.21 & 0.19 \\
\hline 0.827 & 0.65 & 0.62 & 0.231 & 0.22 & 0.32 \\
\hline 0.094 & 0.17 & 0.2 & 0.176 & 0.11 & 0.19 \\
\hline 2.301 & 1.66 & 1.76 & 0.105 & 0.094 & 0.094 \\
\hline 0.407 & 0.37 & 0.57 & 0.551 & 0.69 & 0.48 \\
\hline 0.18 & 0.18 & 0.16 & 0.057 & 0.06 & 0.04 \\
\hline 1.289 & 1.04 & 1.2 & 0.116 & 0.28 & 0.1 \\
\hline
\end{tabular}

Table 5 showed the optimum value, or combination of different process parameters on which the bacterial growth measured by optical density (OD) was maximum for L. acidophilus.

Table 5 - Optimum value of process parameters for Lactobacillus acidophilus.

\begin{tabular}{ll}
\hline $\begin{array}{l}\text { Optimum values of process } \\
\text { parameters }\end{array}$ & L.acidophilus \\
\hline Temperature, $\left({ }^{\circ} \mathrm{C}\right)$ & 37.7 \\
$\mathrm{pH}$ & 6.08 \\
Inoculums volume, $(\mathrm{ml})$ & 0.79 \\
Inoculums age, $(\mathrm{h})$ & 13.04 \\
Carbon content, $(\%) \mathrm{w} / \mathrm{v}$ & 42.62 \\
Nitrogen content, $(\%) \mathrm{w} / \mathrm{v}$ & 39.92 \\
\hline
\end{tabular}

\section{CONCLUSION}

In the present study, RSM and ANN methodologies were used to predict the growth model for L. acidophilus and optimized the growth parameters. Both the models provided similar quality predictions for the above independent variables for the growth conditions of $L$. acidophilus with ANN showing more accuracy in estimation. Regression coefficient $\left(R^{2}\right)$ of ANN and RSM reflected that ANN was better than RSM. RSM was useful in getting insight information (e.g. interactions between different components) of the system directly, but ANN was also equally useful in the sensitivity analysis. 
ANN showed better modeling technique for data set showing nonlinear relationship over RSM. Thus, ANN could be a very powerful and flexible tool well suited for the development of empirical growth model due to an implicit corrective action arising from the training methodology and the associated estimation procedure. Present results showed that the higher cell mass yield of $L$. acidophilus was observed at $37.7^{\circ} \mathrm{C}, \mathrm{pH} 6.08$, inoculum volume and age $0.79 \mathrm{ml}$ and $13.04 \mathrm{~h}$, respectively, carbon content $42.62 \%(\mathrm{w} / \mathrm{v})$ and nitrogen content $(39.92 \%(\mathrm{w} / \mathrm{v})$. This combination of independent variables could be of good importance to starter culture producing industries in order to scale- up the production of $L$. acidophilus on commercial scale more economically due to high cell mass yield.

\section{REFERENCES}

Ballongue J. Bifidobacteria and probiotic action probiotics, the Scientific Basis. J Dairy Sci. 1992; 7: 357-413.

Bhadoria PBS, Mahapatra SC. Prospects, technological aspects and limitations of probiotics - a worldwide review. Eur J Food Res Review. 2011; 2: 23-42.

Biavati B, Vescovo M, Torriabi S, Bottazzi V. Bifidobacteria: history, ecology, physiology and applications. Anal Microbiol. 2000; 50: 117-131.

Coelho LF, Lima CJBD, Rodovalho CM, Bernardo MP, Contiero J. Lactic acid production by new Lactobacillus plantarum LMISM6 grown in molasses: optimization of medium composition. Braz J Chem Eng. 2011; 28: 27-36.

Das H. Empirical model development. Hand Book of Food Processing Operations Analysis. $1^{\text {st }}$ ed. New Delhi: Asian Book Private Limite. 2005; 357-382.

Dutta JR, Dutta PK, Banerjee R. Optimization of culture parameters for extracellular protease production from a newly isolated Pseudomonas sp. using response surface and artificial neural network models. Process Biochem. 2004; 39: 2193-2198.

Gangadharan D, Sivaramakrishnan S, Nampoothiri KM, Sukumaran RK, Pandey A. Response surface methodology for the optimization of alpha amylase production by Bacillus amyloliquefaciens. Bioresour Technol. 2008; 99: 4597-4602.

Kumari A, Mahapatra P, Banerjee R. Statistical optimization of culture conditions by response surface methodology for synthesis of lipase with Enterobacter aerogenes. Braz Arch Biol Technol. 2009; 52: 1349-1356.
Kumari KS, Babu IS, Rao GH. Process optimization for citric acid production from raw glycerol using response surface methodology, Indian $J$ Biotech. 2008; 7: 496-501.

Lima CJBD, Coelho LF, Blanco KC, Contiero J. Response surface optimization of D (-)-lactic acid production by Lactobacillus SMI8 using corn steep liquor and yeast autolysate as an alternative nitrogen source. Afr J Biotechnol. 2009; 8:5842-5846.

Meena GS, Gupta S, Majumdar GC, Banerjee R. Growth characteristics modeling of Bifidobacterium bifidum Using RSM and ANN. Braz Arch Biol Technol. 2011; 54: 1357-1366.

Mitsuoka T. Bifidobacteria and their role in human health. J Ind Microbiol. 1990; 6: 263-268.

Myers RM, Montgomery DC. Response Surface Methodology: Process and Product Optimization Using Designed Experiments. $2^{\text {nd }}$ ed. Hoboken: Wiley-Interscience; 2002.

Nagarjun PA, Rao RS, Rajesham S, Rao LV. Optimization of lactic acid production in SSF by Lactobacillus amylovorus NRRL B-4542 Using Taguchi Methodology. J Microbiol. 2005; 43: 38-43.

Negi S, Banerjee R. Optimization of extraction and purification of glucoamylase produced by Aspergillus awamori in solid state fermentation. Biotech Bioprocess Eng. 2009; 14:60-66.

Rajasekaran S, Vijaylakshmi PGS. Neural Networks Fuzzy Logic and Genetic Algorithms. $1^{\text {st }}$ ed. New Delhi: Prentice Hall of India; 2004.

Sanders ME. Probiotics. Food Biotechnol. 1999; 53: 67-77.

Schezenmeir J, De Vrese M. Probiotics, Prebiotics, and Symbiotic -Approaching a definition. Am J Clin Nutr. 2001; 73: 361-364.

Sen R, Babu KS. Modeling and optimization of the process conditions for biomass production and sporulation of a probiotic culture. Process Biochem. 2005; 40: 2531-2538.

Shah NP. Functional cultures and health benefits. Int Dairy J. 2007; 17: 1262-1277.

Sharma M, Mridula D, Gupta RK. Development of sprouted wheat based probiotic beverage. J Food Sci Technol. 2013; 1-8.

Usmiati S, Marwati T. Selection and optimization process of bacteriocin production from Lactobacillus sp. Indones J Agric. 2009; 2: 82-92.

Ziemer CJ, Gibson GR. An overview of probiotics, prebiotics and symbiotic in the functional food concept: perspectives and future strategies. Int Dairy J. 1998; 8: 473-479. 